\title{
Labyrinthe
}

32 | 2009 (1)

Le petit théâtre intellectuel

\section{Le Polémiste}

\section{Laurent Dubreuil}

\section{(2) OpenEdition}

\section{Journals}

Édition électronique

URL : http://journals.openedition.org/labyrinthe/4231

DOI : 10.4000/labyrinthe.4231

ISSN : 1950-6031

Éditeur

Hermann

Édition imprimée

Date de publication : 19 juin 2009

Pagination : 49-52

ISBN : 978-2-7056-6885-3

\section{Référence électronique}

Laurent Dubreuil, « Le Polémiste », Labyrinthe [En ligne], 32 | 2009 (1), mis en ligne le 01 février 2011, consulté le 19 avril 2019. URL : http://journals.openedition.org/labyrinthe/4231 ; DOI : 10.4000/ labyrinthe.4231 


\section{Le petit théâtre intellectuel}

\section{LE POLÉMISTE}

C'est le matin pour Pamphilet ${ }^{1}$. Au saut du lit, il lui faut trouver une raison de s'indigner, une meilleure cible que la veille, une sourde colère. La vaine contemplation de "l'actualité » pourrait fournir prétexte, un récent envoi (lettre, message, livre) s'avèrerait meilleur encore. Tiens, mais tel crétin vaudois n'a-t-il pas récemment publié un autre ouvrage? Répondons-lui que son culte de la nature donne envie de marcher à quatre pattes, et ne gardons pas la réplique entre nous : l'attaque trouve son sens dans le partage. Le Polémiste se réjouit d'avance du tollé, du remous, des huées. Il va bientôt rentrer dans l'arène avec ses banderilles, sa cape et son collant serré (car il en faut, bien sûr, pour oser affronter ces sauvages ennemis que ses écrits taillent en pièces). Le taureau résistera-t-il? les aficionados seront-ils propices au matador?

En attendant de renifler l'âcre goût du sang, Pamphilet travaille. Quelques heures frénétiques ont suffi pour une dizaine de pages. La polémique, savez-vous, se rédige à toute allure, de peur que l'irritation s'atténue sans doute. Dictée du bon sens, exaspération du nervosisme, vidange du sac à malice. Une ivresse naît de cette rapidité d'exécution, qui se double d'une légère angoisse. Difficile d'exiger de ses lecteurs une pondération, une lente attention que l'on a sciemment écartées. D'où le risque des pamphlets en série, qui, se faisant écho paraît-il, finissent surtout par s'insulter mutuellement pour des positions qu'aucun n'assumait en fait. Bah, les vociférations valent plus que le silence de la chambre.

Eh! regarde ta montre, mon bon Pamphilet, tu es en retard pour te rendre au Club des Intellectuels. Remarque, personne là-bas n'est surpris de te voir arriver à l'heure du dessert, essoufflé, maudissant la race des chauffeurs des taxis dont la nullité mériterait un pamphlet bien senti, à paraître en annexe de ton dernier opus contre les conducteurs de métro, les aiguilleurs du ciel et le sida mental. À tes confrères tu concèdes aussi : « certes, je n'avais pas vu le temps passer, j'étais un peu dans la

1. Le terme de pamphlet dérive du nom pamphilet, qui désignait un court ouvrage, un libelle sur le modèle d'un poème intitulé Pamphile ou de l'amour. 
transe, car je donnais le coup de grâce ». On s'ébahit. Quoi? une nouvelle victime? quelle inventivité, quelle énergie, ce Pampan, toujours prêt à tirer sur tout ce qui bouge!

Au Club pourtant, l'admiration n'est pas entière. Le Renégat numérote ses abattis tout en rêvant que Pamphilet se repentisse un jour de sa passion destructive. L'Expert engage la conversation. Il suit souvent Pamphilet sur le fond - après tout, ne sommes-nous pas membres d'une même société? -, mais la forme, ah là là, la forme... « Pourquoi fais-tu cela? tu t'épuises, l'ami, et c'est mauvais pour ton cœur. » À quoi Pamphilet, peu atténué par le souvenir de son dernier pontage coronarien, rétorque illico «j'agis par amour». Le voici qui se lance dans une obscure justification de son propre nom: oui, il est Pamphile, il aime tout, il se contente de réagir à proportion de son goût pour les choses et la vie, l'imperfection le déçoit trop. Il ajoute, à l'encontre du reproche à peine formulé par l'Éditorialiste, qu'il n'a pas d'intérêt personnel dans cette affaire, qu'il n'en retire aucune jouissance. Gros mensonge, mais Pamphilet parvient presque à convaincre quand il martèle « je fais de la critique, pas de la polémique ». La fumée des cigares monte jusqu'au plafond; chacun se réconcilie, car Pamphilet n'est pas si sérieux ni obstiné, il reste de bonne compagnie. L'harmonie serait parfaite. Las! Cassandre la Pythie, dont personne n'ose résilier l'abonnement au Club par crainte d'une prédiction apocalyptique en guise de représailles, croit utile de conclure autrement et annonce « la fin de la discorde sonnera la fin de ce monde ». Cassandre incarne ce que Pamphilet redouterait de devenir, s'il se prenait à croire ce qu'il écrit.

Nous n'en sommes pas là, et le moment est au débat du soir. Pamphilet quitte le Club dans la voiture de l'Animateur, où tous deux arrangent les détails de la prestation à venir. Les répliques et didascalies sont réglées, le spectacle se réalisera parfaitement. Merci au Débatteur, qui, au cours du débat, jouera excellemment la contrepartie de Pamphilet. Il y a bien des années, ces compères se mirent d'accord pour entretenir leur perpétuel désaccord; ils n'y manquèrent jamais. Leurs matches font parfois un perdant et un gagnant, mais en général ils sont simplement nuls.

Au dîner, Pamphilet médite sur ses exploits du jour. Il est si satisfait qu'il n'en veut pas trop à son steak d'être à point plutôt que saignant, et n'envisage pas en tout cas de se lancer dans une diatribe contre la mauvaise cuisson du bœuf. Alors, fugacement, un doute évanescent 
traverse le contentement: a-t-il toujours évité la bêtise? Il n'oserait trop le jurer. Du moins a-t-il montré une sottise efficace; voilà une consolation. Eh! diable, que d'idées noires tout à coup, il se souvient aussi de la phrase du philosophe disant aucun livre contre quoi que ce soit n'a jamais d'importance. Pamphilet liquide le problème, car il se rappelle que l'auteur de la maxime rédigea ensuite deux forts traités intitulés l'AntiCEdipe. Bien fait. Comme une hésitation s'entête cependant. Pamphilet est-il encore pour quelque chose à force de vivre contre? Hum, la nuit devrait porter conseil.

L.D.

\section{Bibliographie, références, lectures}

I. Gilles Deleuze, «À quoi reconnaît-on le structuralisme?» (1972), L'Île déserte et autres textes, Paris, Minuit, 2002.

II. Henri Meschonnic, "Chaque réponse est une question », URL http:// temporel.fr/Chaque-reponse-est-une-question; consulté le 15 janvier 2009 (et passim dans le Meschonnic d'après les années 1990 pour la distinction entre critique et polémique).

III. Louis Pauwels, « Le Monome des zombies », éditorial du Figaro Magazine, 6 décembre 1986.

IV. Voltaire, lettre du 30 août 1755 à Jean-Jacques Rousseau.

V. Daniel Lindenberg, Le rappel à l'ordre. Enquête sur les nouveaux réactionnaires, Paris, Le Seuil, 2002; Sandra Laugier, Faut-il encore écouter les intellectuels?, Paris, Bayard, 2003; Pierre-André Taguieff, Les Contreréactionnaires, Paris, Denoël, 2007, etc. 